\title{
A Retrograde Transaortic/Transmitral Approach for Radiofrequency Ablation of Adenosine-Sensitive Atrial Tachycardia Arising Near the Apex of Koch's Triangle: A Case Study Approach and Review of the Literature
}

\author{
Jan Hluchy ${ }^{\mathrm{a}, \mathrm{b}}$, Marc Van Bracht ${ }^{\mathrm{a}}$, Bodo Brandts ${ }^{\mathrm{a}}$
}

\begin{abstract}
Atrial tachycardias (ATs) are relatively uncommon and their mechanisms include reentry or may be focal. The characteristics and radiofrequency (RF) ablation of adenosine-sensitive AT arising near the apex of Koch's triangle have been reported. We report a case of successful RF ablation of this tachycardia by using a retrograde transaortic/transmitral approach. An electrophysiological study performed during sinus rhythm showed continuous anterograde atrioventricular nodal and no ventriculoatrial conduction. The tachycardia could be induced and terminated by atrial extrastimulation and rapid atrial pacing. Although inverse resetting response pattern was observed, tachycardia termination by intravenous low-dose adenosine was rather suggestive of triggered activity as the mechanism. The earliest atrial activation was recorded in the His-bundle region. After ineffective right-sided attempts and failure to find earlier atrial activity during mapping the noncoronary sinus of Valsalva, this tachycardia was successfully ablated from the left atrial septum by using a retrograde transaortic/transmitral approach. This report demonstrates the feasibility of a novel retrograde left atrial approach for RF ablation of adenosine-sensitive AT originating from the apex of Koch's triangle.
\end{abstract}

Keywords: Atrial tachycardia; AV nodal reentry; Radiofrequency ablation

\section{Introduction}

Atrial tachycardias (ATs) are relatively uncommon and most of them originate from the right atrium, particularly arising along the crista terminalis [1-6]. The mechanisms of AT include reentry or may be focal due to abnormal automaticity or

Manuscript submitted November 12, 2018, accepted November 26, 2018

${ }^{a}$ Department of Cardiology and Angiology, Augusta-Kranken-Anstalt, Bergstrasse 26, 44791 Bochum, Germany

${ }^{\mathrm{b}}$ Corresponding Author: Jan Hluchy, Department of Cardiology and Angiology, Bergstrasse 26, 44791 Bochum, Germany. Email: hluchy@degedi.de

doi: https://doi.org/10.14740/cr806 triggered activity $[7,8]$. Reports describing a distinct entity of paroxysmal AT originating in the atrioventricular (AV) junction which mimics common or uncommon $\mathrm{AV}$ nodal reentrant tachycardia and can be ablated from the right atrial septum have been published $[9,10]$. We report a case of this tachycardia in which successful radiofrequency (RF) ablation was performed from the left atrial septum by using a retrograde transaortic/transmitral approach.

\section{Case Report}

A 63-year-old woman with no evidence of structural heart disease suffered from recurrent supraventricular long RP tachycardia nonresponsive to beta-blockers. A 12-lead electrocardiogram (ECG) showed a narrow QRS tachycardia at a rate of 130 - 150 beats per minute (bpm), with shallow inverted $P$ waves in the inferior leads and an RP/PR ratio $>1$.

An electrophysiological study was performed using four multipolar catheters with $10 \mathrm{~mm}$ interelectrode spacing (Daig, St. Jude Medical, St. Paul, MN, USA). Quadripolar catheters were used for stimulation and recording from the high right atrium and the right ventricular apex. Two hexapolar catheters were positioned within the coronary sinus for left atrial activity recording and across the tricuspid valve for His-bundle (distal pair) and low right atrial (proximal pair) activity recording. A steerable quadripolar 7-French catheter with a $4 \mathrm{~mm}$ tip electrode (Marinr, Medtronic, Minneapolis, MN, USA) was used for mapping the right atrium, the noncoronary sinus of Valsalva and the left atrium, and temperature-guided RF ablation. Mapping of the left atrium was performed by using a novel retrograde transaortic/transmitral approach. Briefly, the Marinr $\mathrm{MC}$, a steerable multicurve catheter was placed via the femoral artery and advanced into the left ventricle with the catheter tip positioned at the posterolateral mitral annulus from the left ventricular aspect. Then, with a minimum curve $(40 \mathrm{~mm})$ under fluoroscopy and intracardiac recording, the tip was gently deflected (the Tip Deflection Control) and counterclockwise rotated (the Lateral Deflection Control) under careful increasing of the deflected curve (the Curve Radius Control) until the catheter tip was advanced into the left atrium verified by fluoroscopy along with recording a high-amplitude atrial activity. Further steering of the catheter tip using all the three Controls 


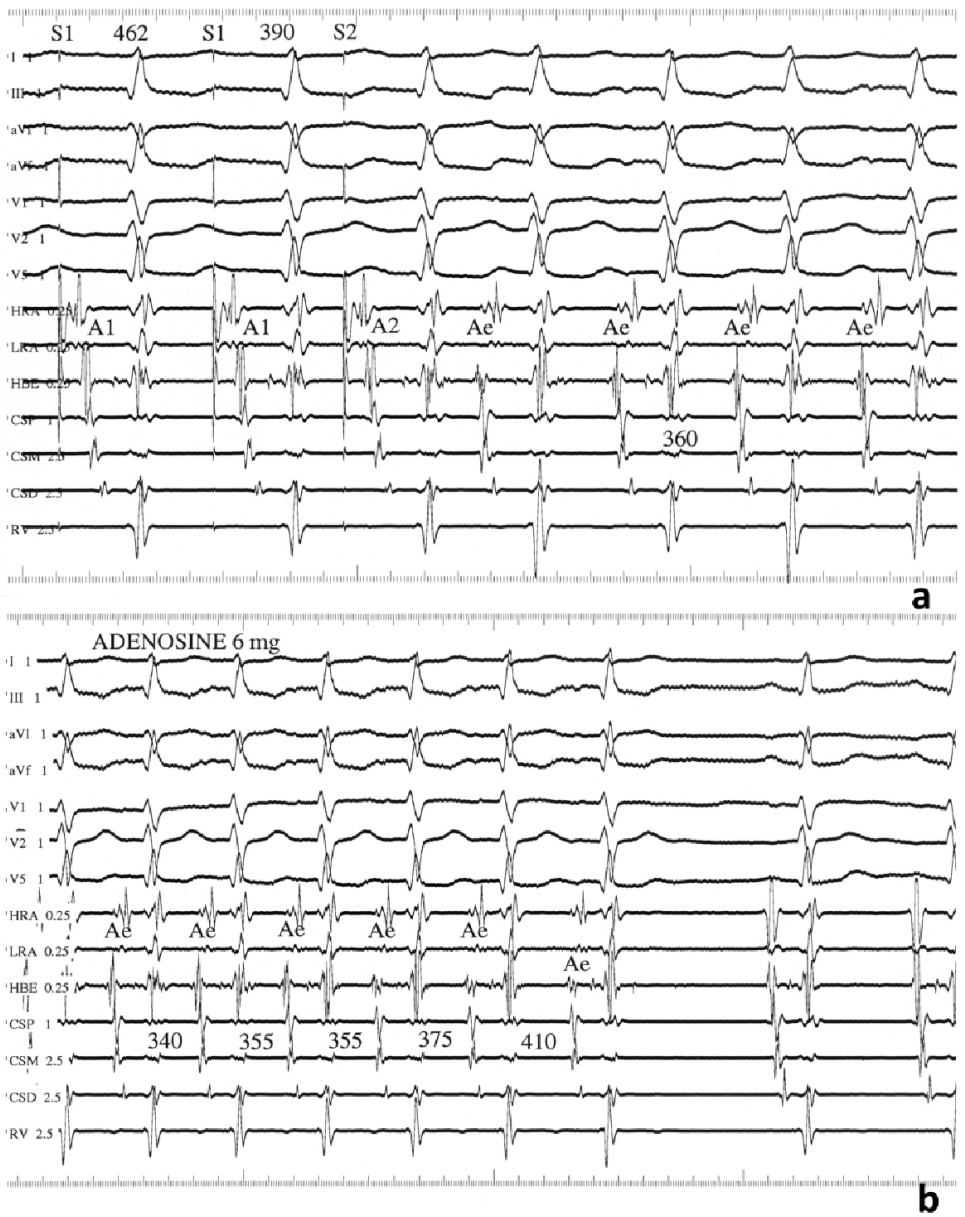

Figure 1. Findings from the electrophysiological study. (a) Intracardiac recordings showing tachycardia induction with an atrial extrastimulus at a prematurity (S1S2) of $390 \mathrm{~ms}$ coupled with a drive cycle length (S1S1) of $462 \mathrm{~ms}$. Paper speed $=100 \mathrm{~mm} / \mathrm{s}$. (b) Tachycardia termination after intravenous bolus of $6 \mathrm{mg}$ adenosine. Paper speed $=75 \mathrm{~mm} / \mathrm{s}$. A1, A2, and Ae: atrial electrograms; CSP, CSM, and CSD: proximal, middle, and distal coronary sinus, respectively; HRA: high right atrium; HBE: His-bundle electrogram; LRA: low right atrium; RV: right ventricular apex.

enabled mapping and ablation in the left atrium.

The electrophysiological study performed during sinus rhythm showed continuous anterograde AV nodal and no ventriculoatrial (VA) conduction. Tachycardia could be induced and terminated by atrial pacing and atrial extrastimulation (Fig. 1a). Tachycardia induction was unrelated to a critical $\mathrm{AH}$ delay and VA dissociation could be demonstrated by ventricular stimulation during tachycardia. The earliest atrial activation was recorded in the His-bundle region. Atrial extrastimulation performed during tachycardia showed an inverse relationship between the reset return cycle and atrial extrastimulus prematurity. Intravenous administration of $6 \mathrm{mg}$ adenosine reproducibly terminated the tachycardia preceded by prolongation of the tachycardia cycle length without developing AV nodal block (Fig. 1b).

Fractionated RF ablation was unsuccessful at the right atrial mid-septum near the apex of Koch's triangle, where a His-bundle was recorded, despite recording an early local atrial activity of $48 \mathrm{~ms}$ before the $\mathrm{P}$ wave. Mapping the noncoronary sinus of Valsalva found no earlier atrial activity. By using a retrograde transaortic/transmitral approach, the ablation catheter was positioned in the low left atrial septum opposite the His-bundle catheter (Fig. 2a, b). Endocardial mapping showed the earliest atrial activity of $52 \mathrm{~ms}$ before the $\mathrm{P}$ wave without a recordable His-bundle potential (Fig. 2c) along with a perfect pace map (Fig. 2d, e). Single RF application at this site resulted in prompt tachycardia termination (Fig. 3) followed by infrequent atrial ectopic beats. After ablation, the tachycardia was no longer inducible and no damage to the AV node was observed.

\section{Discussion}

Reports on AT arising from near the apex of Koch's triangle have been published. The incidence of this tachycardia varies between 0 to $37 \%$ among patients with ATs [9-11]. Factors as patient selection and the fact that this tachycardia mimics common or uncommon AV nodal reentrant tachycardia may be responsible for the varying incidence. It has been speculated 

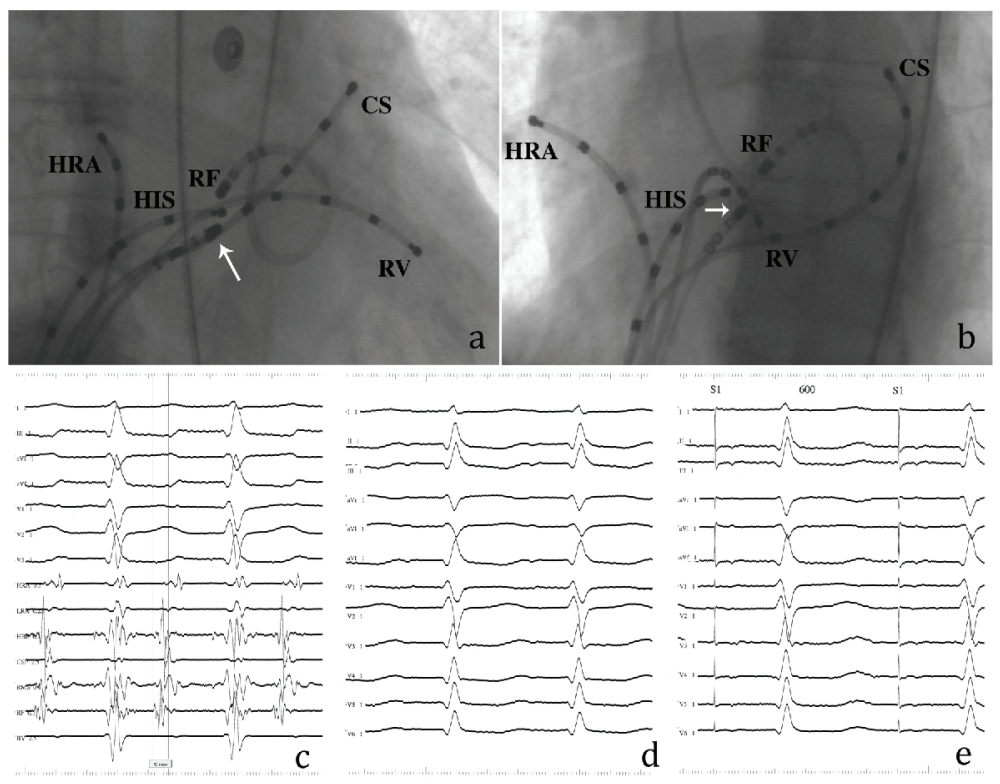

Figure 2. Findings from the retrograde transaortic/transmitral approach. (a) Right anterior oblique and (b) left anterior oblique radiographs of the RF ablation catheter positioned at the successful ablation site of left atrial septum. White arrows indicate the tip of a steerable catheter positioned in the right atrial mid-septum (RMS). (c) Bipolar electrogram from the RF catheter during tachycardia. The local atrial electrogram precedes the P wave by $52 \mathrm{~ms}$ without a recordable His-bundle potential. (d) Twelvelead ECG during tachycardia. (e) Perfect pace map obtained from the successful ablation site. The other abbreviations are shown in Figure 1.

that RF modification of the AV node might cure this tachycardia [10]. However, it remained inducible despite complete AV nodal block caused by ablation and its elimination did not influence dual AV nodal physiology [9].

In the present case, the tachycardia could be terminated by intravenous adenosine. The electrophysiologic findings in our patient were consistent with the diagnosis of adenosinesensitive AT arising from near the apex of Koch's triangle [9]. The mechanism of this tachycardia has been attributed to reentry in the transitional area of the AV node or triggered activity [9, 12-15]. Previous studies have shown successful ablation of this tachycardia from the right atrial septum near the His bundle or AV node without disturbing AV nodal conduction [911]. It has been shown that transseptal mapping and ablation from the left side of the interatrial septum were required for some focal ATs originating from the vicinity of the AV node $[16,17]$. However, the possibility that those ATs are adenosine-sensitive was not studied. As previously reported, some of these ATs can be eliminated by ablation from the noncoronary aortic cusp [18]. RF energy delivery through the aortic sinus of Valsalva is associated with several potential complications including embolic events and the risk of injuring the coronary arteries and perforating the sinus of Valsalva. However, several subsequent studies reported that these ATs can be ablated

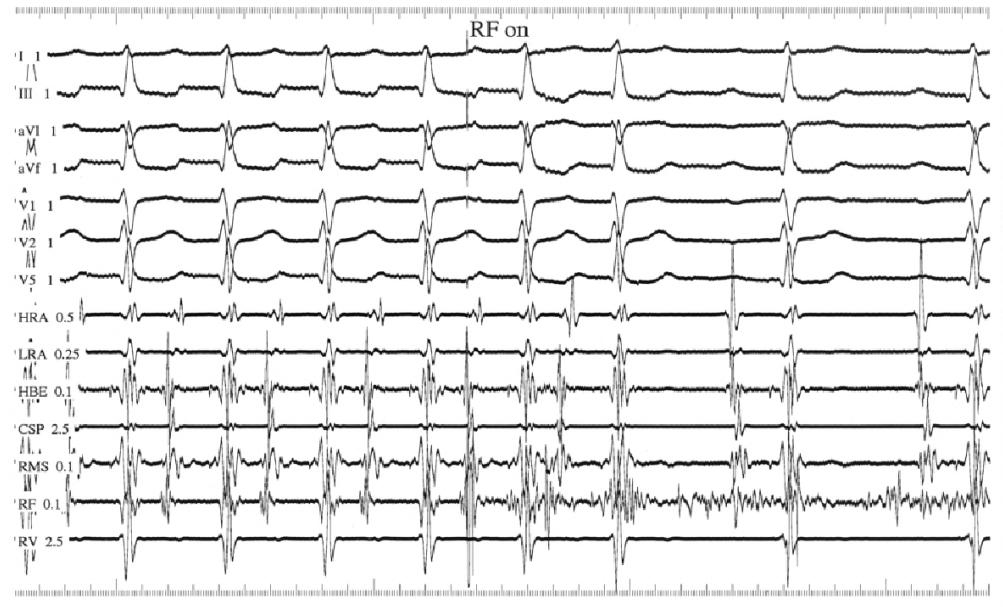

Figure 3. RF ablation of the tachycardia. Delivery of RF energy promptly terminates the tachycardia. 
successfully and complication-free from the noncoronary aortic cusp [17, 19-25]. Although ablated from the noncoronary aortic cusp, both the electrophysiologic characteristics and the sensitivity to adenosine were also suggestive of triggered activity or micro-reentry as a mechanism responsible for this focal AT [19]. These ATs eliminated from the right atrial anterior septum or the noncoronary cusp are believed to be located in the true atrial septum [22]. It has been reported that the minority of ATs conventionally with the earliest atrial activation in the His-bundle region and negative $\mathrm{P}$ waves in leads I and aVL can be located and ablated from the left coronary cusp via a retrograde aortic approach or in the aortic mitral junction via a transseptal approach [17, 26-30]. Mapping the noncoronary sinus of Valsalva in this case found no early activity. Our report is the first one we are aware of demonstrating successful RF ablation from the left atrial septum by using a special technique for the retrograde transaortic/transmitral approach. Our transaortic/transmitral approach seems to be a continuation of an ablation strategy proposed by Wang et al [22], consisting of a right atrial trial, and if needed, followed by a retrograde aortic approach. In case of failure of this strategy in AT with negative $\mathrm{P}$ waves in leads I and aVL, our approach may enable left atrial mapping and ablation in the aortic mitral junction, as successfully done in our another case (unpublished data). In one case reported by Joung et al [31], no early atrial activation was found in the left atrium using a retrograde transaortic approach and successful AT ablation was performed from the noncoronary aortic cusp. However, in their case, radiographs showed that the left atrial catheter was placed deep in the left atrium far away from the left basal anterior septum. The fact that AV junctional cells histologically similar to atrial cells but resembling nodal cells in their cellular electrophysiology and response to adenosine have been found around both AV annuli $[27,32-35]$ is in support of the possibility that this adenosinesensitive tachycardia can be located and ablated on the left side of the interatrial septum.

For ATs that are inducible and terminable with stimulation, discrimination between intra-atrial reentry and triggered activity may be difficult. Atrial reentry tachycardia was usually characterized by an inverse resetting response pattern, whereas triggered AT was designed for those with a direct resetting response $[9,36,37]$. In eight of nine patients with triggered AT with demonstrable delayed afterdepolarization in monophasic action potential, mixed and inverse types of resetting response pattern were found in six and two patients, respectively [36]. Similar findings were also reported by others [38, 39]. Thus, inverse resetting response pattern does not appear to be specific for reentry. Therefore, tachycardia termination by intravenous low-dose adenosine was rather suggestive of triggered activity as the mechanism in our case [40]. However, the possibility that the mechanism of this focal tachycardia is microreentry $[9,12]$ or reentry in a small circuit due to markedly nonuniform anisotropic conduction properties [41] cannot be excluded. As reported in the latter study, nonuniform anisotropic cellular coupling, which is associated with underlying microfibrosis, makes it possible for reentry to occur in small areas $\left(<10-15 \mathrm{~mm}^{2}\right)$.

In conclusion, our findings demonstrate the feasibility of retrograde left atrial ablation of adenosine-sensitive tachycar- dia arising from near the apex of Koch's triangle. We believe that patients with unsuccessful right-sided ablation of this tachycardia may require a left atrial approach to eliminate it.

\section{Conflict of Interest}

The authors declare that there is no conflict of interest or financial relationship regarding the publication of this paper.

\section{Consent}

The patient gave her informed consent prior to inclusion in the study and the ethics committee approval was obtained.

\section{Abbreviations}

AT: atrial tachycardia; AV: atrioventricular; RF: radiofrequency; ECG: electrocardiogram; bpm: beats per minute; VA: ventriculoatrial

\section{References}

1. Shenasa H, Merrill JJ, Hamer ME, Wharton JM. Distribution of ectopic atrial tachycardias along the crista terminalis: An atrial ring of fire? Circulation. 1993;88(suppl I): $1-29$.

2. Ross DL, Denniss AR, Uther JB. Electrophysiologic study in supraventricular arrhythmias. Cardiovasc Clin. 1985;15(1):187-213.

3. Kay GN, Chong F, Epstein AE, Dailey SM, Plumb VJ. Radiofrequency ablation for treatment of primary atrial tachycardias. J Am Coll Cardiol. 1993;21(4):901-909.

4. Tracy CM, Swartz JF, Fletcher RD, Hoops HG, Solomon AJ, Karasik PE, Mukherjee D. Radiofrequency catheter ablation of ectopic atrial tachycardia using paced activation sequence mapping. J Am Coll Cardiol. 1993;21(4):910-917.

5. Steinbeck G, Hoffmann E. 'True' atrial tachycardia. Eur Heart J. 1998;19(Suppl E):E10-12, E48-19.

6. Kalman JM, Olgin JE, Karch MR, Hamdan M, Lee RJ, Lesh MD. "Cristal tachycardias": origin of right atrial tachycardias from the crista terminalis identified by intracardiac echocardiography. J Am Coll Cardiol. 1998;31(2):451-459.

7. Chen SA, Chiang CE, Yang CJ, Cheng CC, Wu TJ, Wang $\mathrm{SP}$, Chiang BN, et al. Radiofrequency catheter ablation of sustained intra-atrial reentrant tachycardia in adult patients. Identification of electrophysiological characteristics and endocardial mapping techniques. Circulation. 1993;88(2):578-587.

8. Lesh MD, Van Hare GF, Epstein LM, Fitzpatrick AP, Scheinman MM, Lee RJ, Kwasman MA, et al. Radiofrequency catheter ablation of atrial arrhythmias. Results and mechanisms. Circulation. 1994;89(3):1074-1089. 
9. Iesaka Y, Takahashi A, Goya M, Soejima Y, Okamoto Y, Fujiwara H, Aonuma K, et al. Adenosine-sensitive atrial reentrant tachycardia originating from the atrioventricular nodal transitional area. J Cardiovasc Electrophysiol. 1997;8(8):854-864.

10. Lai LP, Lin JL, Chen TF, Ko WC, Lien WP. Clinical, electrophysiological characteristics, and radiofrequency catheter ablation of atrial tachycardia near the apex of Koch's triangle. Pacing Clin Electrophysiol. 1998;21(2):367374.

11. Tada H, Nogami A, Naito S, Suguta M, Nakatsugawa M, Horie Y, Tomita T, et al. Simple electrocardiographic criteria for identifying the site of origin of focal right atrial tachycardia. Pacing Clin Electrophysiol. 1998;21(11 Pt 2):2431-2439.

12. Markowitz SM, Stein KM, Mittal S, Slotwiner DJ, Lerman BB. Differential effects of adenosine on focal and macroreentrant atrial tachycardia. J Cardiovasc Electrophysiol. 1999;10(4):489-502.

13. Yamabe H, Tanaka Y, Morihisa K, Uemura T, Enomoto $\mathrm{K}$, Kawano H, Ogawa H. Analysis of the anatomical tachycardia circuit in verapamil-sensitive atrial tachycardia originating from the vicinity of the atrioventricular node. Circ Arrhythm Electrophysiol. 2010;3(1):54-62.

14. Chen FC, Asirvatham SJ. Tachycardia and the AV nodal region: guilt by association? Circ Arrhythm Electrophysiol. 2010;3(1):2-6.

15. Okumura K, Sasaki S, Kimura M, Horiuchi D, Sasaki K, Itoh T, Tomita H, et al. Usefulness of combined CARTO electroanatomical mapping and manifest entrainment in ablating adenosine triphosphate-sensitive atrial tachycardia originating from the atrioventricular node vicinity. J Arrhythm. 2016;32(2):133-140.

16. Frey B, Kreiner G, Gwechenberger M, Gossinger HD. Ablation of atrial tachycardia originating from the vicinity of the atrioventricular node: significance of mapping both sides of the interatrial septum. J Am Coll Cardiol. 2001;38(2):394-400.

17. Wang Z, Liu T, Shehata M, Liang Y, Jin Z, Liang M, Han $\mathrm{Y}$, et al. Electrophysiological characteristics of focal atrial tachycardia surrounding the aortic coronary cusps. Circ Arrhythm Electrophysiol. 2011;4(6):902-908.

18. Tada H, Naito S, Miyazaki A, Oshima S, Nogami A, Taniguchi K. Successful catheter ablation of atrial tachycardia originating near the atrioventricular node from the noncoronary sinus of Valsalva. Pacing Clin Electrophysiol. 2004;27(10):1440-1443.

19. Ouyang F, Ma J, Ho SY, Bansch D, Schmidt B, Ernst $\mathrm{S}$, Kuck KH, et al. Focal atrial tachycardia originating from the non-coronary aortic sinus: electrophysiological characteristics and catheter ablation. J Am Coll Cardiol. 2006;48(1):122-131.

20. Liu X, Dong J, Ho SY, Shah A, Long D, Yu R, Tang R, et al. Atrial tachycardia arising adjacent to noncoronary aortic sinus: distinctive atrial activation patterns and anatomic insights. J Am Coll Cardiol. 2010;56(10):796-804.

21. Beukema RJ, Smit JJ, Adiyaman A, Van Casteren L, Delnoy PP, Ramdat Misier AR, Elvan A. Ablation of focal atrial tachycardia from the non-coronary aortic cusp: case series and review of the literature. Europace. 2015;17(6):953-961.

22. Wang Z, Ouyang J, Liang Y, Jin Z, Yang G, Liang M, Li $\mathrm{S}$, et al. Focal atrial tachycardia surrounding the anterior septum: strategy for mapping and catheter ablation. Circ Arrhythm Electrophysiol. 2015;8(3):575-582.

23. Yamashita S, Yamane T, Matsuo S, Ito K, Narui R, Hioki M, Nakane T, et al. A case of adenosine sensitive atrial tachycardia originating from the His-bundle region successfully ablated from the non-coronary aortic cusp. Journal of Arrhythmia. 2010;26(1):44-49.

24. Mulpuru SK, Holland MC, Narayan SM. Adenosine Responsive Narrow Complex Tachycardia: What is the Mechanism? The Journal of Innovations in Cardiac Rhythm Management. 2011;2:226-229.

25. Koca S, Topaloglu S, Cay S, Pac A. Electroanatomic mapping-guided radiofrequency ablation of adenosine sensitive incessant focal atrial tachycardia originating from the non-coronary aortic cusp in a child. Indian Pacing Electrophysiol J. 2014;14(5):258-262.

26. Kistler PM, Sanders P, Hussin A, Morton JB, Vohra JK, Sparks PB, Kalman JM. Focal atrial tachycardia arising from the mitral annulus: electrocardiographic and electrophysiologic characterization. J Am Coll Cardiol. 2003;41(12):2212-2219.

27. Gonzalez MD, Contreras LJ, Jongbloed MR, Rivera J, Donahue TP, Curtis AB, Bailey MS, et al. Left atrial tachycardia originating from the mitral annulus-aorta junction. Circulation. 2004;110(20):3187-3192.

28. Otomo K, Azegami K, Sasaki T, Kawabata M, Hirao K, Isobe M. Successful catheter ablation of focal left atrial tachycardia originating from the mitral annulus aorta junction. Int Heart J. 2006;47(3):461-468.

29. Morishima I, Sone T, Tsuboi H, Mukawa H, Uesugi M. Adenosine-sensitive focal reentrant tachycardia originating from the mitral annulus-aorta junction. Journal of Arrhythmia. 2008;24(4):209-213.

30. Kino N, Kurotobi T, Tonomura D, Yano K, Furubayashi K, Tsuchida T, Shimada Y, et al. Adenosine-sensitive atrial tachycardia originating from the mitral annulus-aorta junction. Journal of Arrhythmia, 2014;30(3):197-200.

31. Joung B, Lee MH, Kim SS. Successful catheter ablation of atrial tachycardia originating from the non-coronary aortic sinus. Yonsei Med J. 2008;49(6):1041-1045.

32. McGuire MA, de Bakker JM, Vermeulen JT, Moorman AF, Loh P, Thibault B, Vermeulen JL, et al. Atrioventricular junctional tissue. Discrepancy between histological and electrophysiological characteristics. Circulation. 1996;94(3):571-577.

33. Nakamura T, Hachiya H, Tanaka Y, Yagishita A, Sugiyama K, Suzuki M, Kawabata M, et al. Distribution of the origin of adenosine triphosphatesensitive atrial tachycardias with the earliest activation recorded in the His bundle catheter: are they limited to the immediate vicinity of the His bundle? Circ J. 2013;77(3):626-631.

34. Matsuoka K, Kasai A, Fujii E, Omichi C, Okubo S, Teramura S, Uchida F, et al. Electrophysiological features of atrial tachycardia arising from the atrioventricular annulus. Pacing Clin Electrophysiol. 2002;25(4 Pt 1):440-445. 
35. Morton JB, Sanders P, Das A, Vohra JK, Sparks PB, Kalman JM. Focal atrial tachycardia arising from the tricuspid annulus: electrophysiologic and electrocardiographic characteristics. J Cardiovasc Electrophysiol. 2001;12(6):653-659.

36. Chen SA, Chiang CE, Yang CJ, Cheng CC, Wu TJ, Wang SP, Chiang BN, et al. Sustained atrial tachycardia in adult patients. Electrophysiological characteristics, pharmacological response, possible mechanisms, and effects of radiofrequency ablation. Circulation. 1994;90(3):12621278.

37. Wen MS, Yeh SJ, Wang CC, Lin FC, Wu D. Radiofrequency ablation therapy in three patients with paroxysmal atrial tachycardia. Pacing Clin Electrophysiol.
1993;16(11):2146-2156.

38. Hluchy J, Milovsky V, Uhliarikova H. Triggered activity as the proposed mechanism of left atrial tachycardia induced by premature ventricular beats. Int J Cardiol. 1992;34(3):342-345.

39. Hiraoka M. Characteristics of triggered-activity and delayed afterdepolarization in responses to the electrical stimulation. Jpn Circ J. 1987;51(2):176-180.

40. Engelstein ED, Lippman N, Stein KM, Lerman BB. Mechanism-specific effects of adenosine on atrial tachycardia. Circulation. 1994;89(6):2645-2654.

41. Spach MS, Josephson ME. Initiating reentry: the role of nonuniform anisotropy in small circuits. J Cardiovasc Electrophysiol. 1994;5(2):182-209. 